\title{
LESSONS LEARNED FROM MODERN SLAVERY: ADDRESSING SHARED CHALLENGES IN MEASUREMENT FOR STATELESSNESS RESEARCHERS
}

\author{
DAVINA P DURGANA*
}

TABLE OF CONTENTS

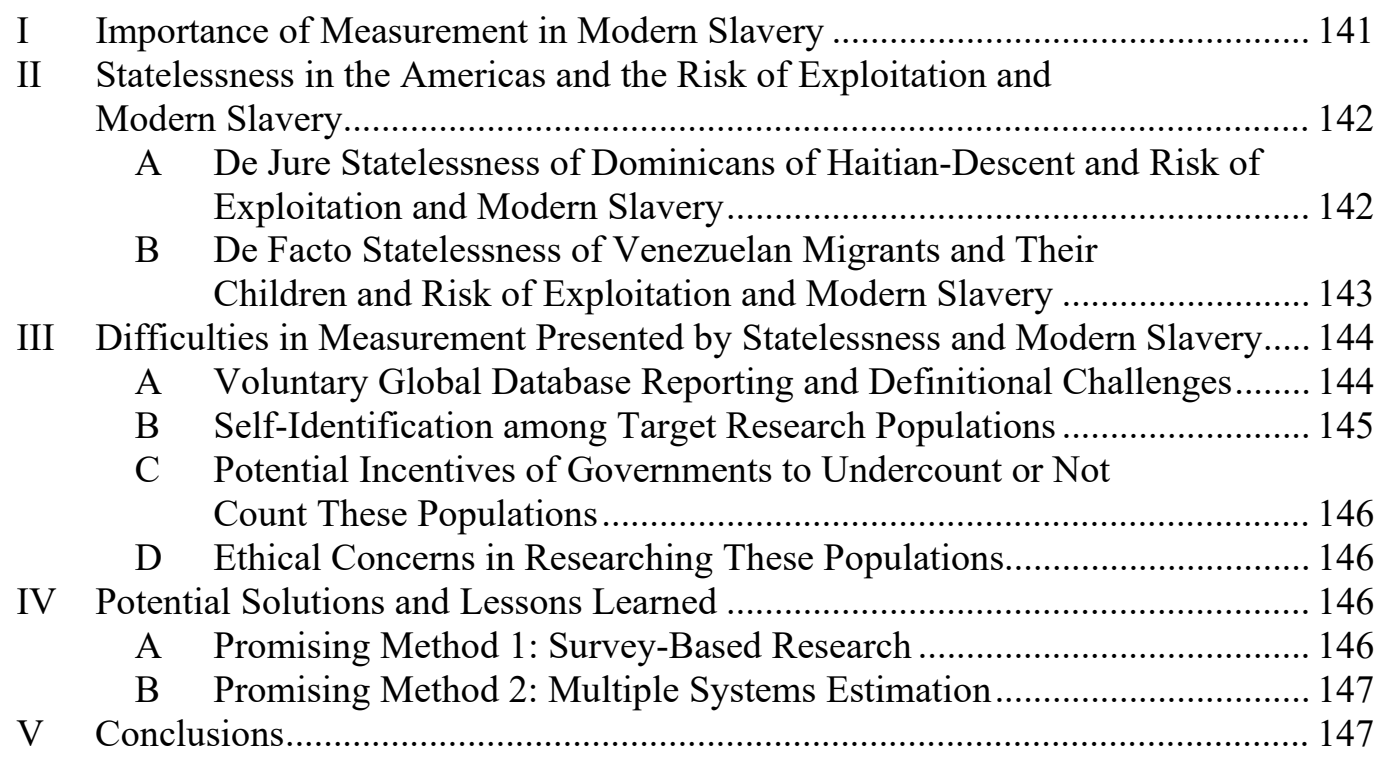

\section{IMPORTANCE OF MEASUREMENT IN MODERN SLAVERY}

Modern slavery and statelessness research efforts present an opportunity for a collaborative and shared research agenda. This discussion focuses on the importance of measurement for both modern slavery and statelessness research, a proposed shared research agenda for statelessness and modern slavery in the Americas, and challenges statelessness researchers face that can be addressed by best practices from the modern slavery field. This discussion is informed by the work of Walk Free - made possible by the Minderoo Foundation - a leader in the modern slavery space and producer of the Global Slavery Index (' GSI'). ${ }^{1}$ The $G S I$ is the world's most comprehensive study on the prevalence of modern slavery and enables us to refine our thinking on how to better respond to this crime, and

* Dr Durgana is Senior Statistician at the Walk Free initiative of the Minderoo Foundation with over a decade of experience in the modern slavery field. She is Vice Chair of Statistics without Borders, an American Statistical Association Statistical Advocate of the Year, a Forbes Under 30 Board Member and an AAAS If/Then Ambassador. Dr Durgana also holds faculty membership at Oxford University.

1 'Walk Free', Minderoo Foundation (Web Page, 2020) <https://www.minderoo.org/walkfree/>. 
how to prevent modern slavery in the future. ${ }^{2}$ Effective measurement of modern slavery is the cornerstone of evidence-based policy making in our field and can have a similarly powerful impact on statelessness research. This symposium on the challenges, solutions and best practices of measurement in modern slavery and how it can inform statelessness research - is a critical opportunity to ensure that all stakeholders feel empowered to interpret and use our collective findings.

\section{StATELESSNESS IN THE AMERICAS AND THE RisK OF EXPLOITATION AND}

\section{MODERN SLAVERY}

Statelessness increases risk of modern slavery and presents an opportunity for a shared research agenda, particularly in the Americas. Despite increased media coverage of modern slavery throughout the region, statelessness might not be the first issue that we consider when we think of the Americas. ${ }^{3}$ However, over the past six years, the vulnerabilities to statelessness resulting from the Venezuelan crisis and the citizenship stripping of Dominicans of Haitian descent have propelled the Americas into prominent focus in statelessness discussions. ${ }^{4}$ Importantly, the Americas remains a region with strong domestic legislative precedent for citizenship provisions and, therefore, a potential opportunity for meaningful action to address statelessness and its inherent risk of exploitation. ${ }^{5}$ Multiple components of the GSI Global Vulnerability Model correspond to the risks that stateless persons face in the Americas and around the world, including adverse effects from governance issues, lack of basic needs, inequality, membership in disenfranchised groups and effects of conflict, including risk of internal displacement. ${ }^{6}$ Challenges in measuring statelessness powerfully overlap with challenges in measuring modern slavery as an important focal point for research and motivating political action in both fields. In particular, risk of exploitation and modern slavery among stateless populations warrants further consideration. These intersecting research interests can be pursued in the Americas region through the following opportunities for a joint research agenda on statelessness and modern slavery.

\section{A De Jure Statelessness of Dominicans of Haitian-Descent and Risk of}

\section{Exploitation and Modern Slavery}

De jure stateless persons, those who are unable to invoke the protection of any state, are the most commonly understood form of statelessness under the United

2 Global Slavery Index (Report, Walk Free Foundation 2018) <globalslaveryindex.org> ('GSI').

3 Laura Van Waas, Amal de Chickera and Zahra Albarazi, 'The World's Stateless: A New Report on Why Size Does and Does Not Matter', European Network on Statelessness (Blog Post, 15 December 2014) <https://www.statelessness.eu/blog/world\%E2\%80\%99s-statelessnew-report-why-size-does-and-doesn $\%$ E2\%80\%99t-matter $>$.

4 The World's Stateless: Deprivation of Nationality (Report, Instute on Statelessness and Inclusion March 2020) 65-68 ('The World's Stateless') $<\mathrm{https}$ ://www.institutesi.org/resources/worlds-stateless-2020>.

5 ibid 55.

6 Minderoo Foundation, '2018 Methodology: Vulnerability', Global Slavery Index (Web Page, 2018 ) <https://www.globalslaveryindex.org/2018/methodology/vulnerability/>; GSI (n 2). 
Nations Statelessness Conventions. ${ }^{7}$ An example of de jure statelessness includes the situation of Dominicans of foreign and Haitian descent who were stripped of their Dominican citizenship after a constitutional change. ${ }^{8}$ In 2013, the Dominican Republic created the world's fifth-largest stateless population when citizenship was revoked for all descendants of foreign-born parents dating back to 1929. ${ }^{9}$ This ruling predominantly affected Dominicans of Haitian descent who had been migrating for decades from Haiti to the Dominican Republic due to natural and economic disasters in Haiti. ${ }^{10}$

In 2018-19, the United States of America Department of State, Free the Slaves and the International Association of Women Judges collaborated with local community partners throughout the Dominican Republic to address the generations of Dominicans of Haitian descent who lack legal work authorisation in the Dominican Republic and who therefore remain highly vulnerable to exploitation and modern slavery. ${ }^{11}$ These populations do not have Haitian Creole language abilities, nor have they ever lived outside of the Dominican Republic. Work opportunities for these populations are limited to low-wage and high-risk informal industries where they labour under constant fear of arbitrary deportation and incarceration because of this constitutional change.

\section{B De Facto Statelessness of Venezuelan Migrants and Their Children and}

\section{Risk of Exploitation and Modern Slavery}

A broader view of statelessness can situate the plight of stateless persons within refugee crises. This is relevant in the context of de facto stateless persons where persons with a nationality, but who are not able to obtain necessary protection or benefits from that status, can also be considered effectively stateless. ${ }^{12}$ De facto statelessness issues are pervasive in the survival migration undertaken by millions of Venezuelans following the socioeconomic and political crises beginning in 2010. These individuals cannot effectively access the protection or benefits of their nationality, thus meeting the definition of a de facto stateless person, and may be seen today in the plight of those whose birth records never existed or were destroyed, or those who are marginalised within their national community and excluded from commensurate protection by their state. ${ }^{13}$

7 Convention Relating to the Status of Stateless Persons, opened for signature 28 September 1954, 360 UNTS 117 (entered into force 6 June 1960); Convention on the Reduction of Statelessness, opened for signature 30 August 1961, 989 UNTS 185 (entered into force 13 December 1975).

8 'Haiti: Stateless People Trapped by Poverty — Victims of Dominican Republic's Arbitrary Deportations', Human Rights Watch (Web Page, 29 November 2016) $<$ https://www.hrw.org/news/2016/11/29/haiti-stateless-people-trapped-poverty\#>.

9 Leah Libresco, 'The Dominican Republic's Revocation of Citizenship Creates 200,000 Stateless People', FiveThirtyEight (online, 17 June 2015) $<$ https://fivethirtyeight.com/features/the-dominican-republics-revocation-of-citizenshipcreates-200000-stateless-people/>.

10 ibid

11 'Slavery in the Dominican Republic', Free the Slaves (Web Page) $<$ https://www.freetheslaves.net/where-we-work/dominican-republic/>.

12 Clay Collins and David Weissbrodt, 'The Human Rights of Stateless Persons' (2006) 28(1) Human Rights Quarterly 245, 251-52.

13 Hugh Massey, Legal and Protection Policy Research Series: UNHCR and De Facto Statelessness, UN Doc LPPR/2010/01 (April 2010) 42, 61-62; Nick Cheesman, 'Problems with Facts about Rohingya Statelessness' [2018] E-International Relations Articles $<$ https://www.e-ir.info/2015/12/08/problems-with-facts-about-rohingya-statelessness/>. 
As many as 8,200 pregnant Venezuelan women have entered Colombia since 2018 with no assurances that their children will be granted citizenship under Colombia's nationality laws, effectively rendering these children stateless. ${ }^{14}$ Venezuelans are often also unable to access personal identification documents to obtain status in Colombia, further enhancing their effective statelessness and subsequent vulnerability to exploitation and modern slavery. ${ }^{15}$ Venezuelan women and girls in Colombia are often forced to work in high-risk and low-wage industries including sex trafficking in border communities and larger cities such as Cucuta and Cartagena. ${ }^{16}$ Modern slavery research focuses on identifying hidden populations, and stateless persons of all types are among the hidden populations vulnerable to exploitation that we must also find.

\section{Difficulties in Measurement Presented by Statelessness AND}

\section{MODERN SLAVERY}

Several of the challenges in counting stateless persons highlighted by statelessness researchers are present in modern slavery research. ${ }^{17}$ This section will address challenges in both statelessness and modern slavery scholarship related to: A) global database reporting and definitional challenges, B) self-identification among target research populations, C) potential incentives of governments to undercount or not count these populations, and D) ethical concerns in research. This section includes promising methods used in the modern slavery field that may improve current measurement efforts in statelessness research.

\section{A Voluntary Global Database Reporting and Definitional Challenges}

The United Nations High Commissioner for Refugees ('UNHCR') Global Trends: Forced Displacement in 2017 report measurement of statelessness relies on country operations to provide estimates of these populations. ${ }^{18}$ Reliance on statelessness reporting to UNHCR is similar to the role of the UN Office on Drugs and Crime's ('UNODC') Global Report on Trafficking in Persons ('GLOTIP'). ${ }^{19}$ GLOTIP depends on voluntary reporting of participating states with similar comparability and data capacity challenges. In both fields, there is a global need for greater data management capacity and coordinated data collection standards and shared methodology. ${ }^{20}$

Definitional challenges in modern slavery research include varying national standards that are not always comparable across countries. These issues are similar to challenges in identifying stateless persons that may be excluded due to other

14 Lucía Ramirez Bolivar and Silvia Ruiz, 'Babies without a Homeland That the Venezuelan Exodus May Leave in Colombia', Dejusticia (Web Page, 2018) $<$ https://www.dejusticia.org/en/babies-without-a-homeland-that-the-venezuelan-exodusmay-leave-in-colombia/>.

15 The World's Stateless (n 4) 67-68.

16 Forthcoming research by Minderoo Foundation, 2020.

17 Van Waas, de Chickera and Albarazi (n 3).

18 United Nations High Commissioner for Refugees, Global Trends: Forced Displacement in 2017 (Report, 2017) ('Global Trends 2017) <https://www.unhcr.org/globaltrends2017/>.

19 Global Report on Trafficking in Persons (Report, United Nation Office on Drugs and Crime, December 2018) <https://www.unodc.org/unodc/data-and-analysis/glotip.html $>$.

20 Lily Chen, Petra Nahmias and Sebastian Steinmuller, UNHCR Statistical Reporting on Statelessness (Report, UNHCR $\quad$ October 2019 ) 12-13 $<$ https://www.unhcr.org/5d9e182e7.pdf $>$. 
UN conventions related to refugees, internally displaced persons and asylum seekers. $^{21}$ While varying national definitions always complicate global measurement, statelessness research is further complicated by unclear definitional parameters around de facto statelessness and international guidelines. As a potential solution, the $19^{\text {th }}$ International Conference of Labour Statisticians adopted Resolution II: Resolution Concerning Further Work on Statistics of Forced Labour to establish a working group to share best practices in forced labour surveys globally. ${ }^{22}$ Data capacity and reporting issues in statelessness research might be ameliorated with the formation of another working group focused on global best practices to address statelessness that may be used to develop field-wide standards.

\section{B Self-Identification among Target Research Populations}

An issue that arises in both statelessness and modern slavery contexts includes an unwillingness or lack of awareness by research participants to self identify as a stateless or an enslaved person. Often many people in these situations are unaware of the labels that Western researchers may place on them, and it can sometimes become detrimental to their personal resilience to be labelled as a victim of either circumstance. ${ }^{23}$ Particularly in the context of labour trafficking, discrepancies between legal definitions and lived experiences may account for low rates of selfidentification. ${ }^{24}$

In the modern slavery field, this challenge is typically mitigated by multiple rounds of cognitive testing and the inclusion of survey items on conditions such as force, fraud and coercion to validate self-responses. ${ }^{25}$ For example, it is possible that someone might respond that they are not experiencing forced labour, but based on the work conditions that they describe, we may consider that circumstance to represent a situation of modern slavery. Similarly, in statelessness research, surveys can be adjusted to include questions on the details of individual situations that will help clarify the specific circumstance of each respondent for researchers.

21 See, eg, Convention Relating to the Status of Refugees, opened for signature 28 July 1951, 189 UNTS 137 (entered into force 22 April 1954).

22 Resolution II: Resolution Concerning Further Work on Statistics of Forced Labour, cited in Report of the Conference: $19^{\text {th }}$ International Conference of Labour Statisticians (Report ICLS/19/2013/3, International Labour Office, October 2013) 66; 'Statistics on Forced Labour, Modern Slavery and Human Trafficking', International Labour Organization (Web Page) $<$ https://www.ilo.org/global/topics/forced-labour/statistics/lang--en/index.htm>.

23 Victims of Modern Slavery - Frontline Staff Guidance (Guidance, United Kingdom Home $\begin{array}{llll}\text { Office } & 18 & \text { March 2016) 20-21 }\end{array}$ $<$ https://www.antislaverycommissioner.co.uk/media/1057/victims-of-modern-slaveryfrontline-staff-guidance-v3.pdf $>$.

24 Masja van Meeteren and Jing Hiah, 'Self-Identification of Victimization of Labor Trafficking' in John Winterdyk and Jackie Jones (eds), Palgrave International Handbook of Human Trafficking (Palgrave Macmillan 2019) 1605.

25 Jacqueline Joudo Larsen and Pablo Diego-Rosell, 'Using Surveys to Estimate the National Prevalences of Modern Slavery: Experience and Lessons Learned' (2017) 30(3) CHANCE $30,31-32$. 


\section{Potential Incentives of Governments to Undercount or Not Count These}

\section{Populations}

A similar challenge that both statelessness and modern slavery researchers share are governments that may either suppress target population statistics or be unwilling to count them at all. Often, governments are concerned with the impact of this data on their national reputations. In the case of modern slavery, there is a concern that poor performance may affect non-humanitarian and non-trade related foreign assistance from the US through the Trafficking in Persons Report. ${ }^{26}$ For instance, the Dominican Republic's reported figures for statelessness were flagged in the 2017 UNHCR Global Trends report as potentially incomplete due to their ongoing efforts to address their statelessness issues. ${ }^{27}$ A potential way to overcome this hesitation by national governments is to incentivise measurement through UN commitments and public support for ongoing measurement efforts.

\section{Ethical Concerns in Researching These Populations}

Measurement of statelessness and modern slavery is fraught with ethical concerns on how to best protect vulnerable populations through this research. Ethical research standards must uphold the safety of research subjects above all others. ${ }^{28}$ For example, research on modern slavery in the United States must account for changes to immigration enforcement policy that has placed both modern slaves and stateless persons at risk of deportation if other asylum or trafficking-related protections are denied. ${ }^{29}$ In modern slavery research, prioritising the protection of research respondents from unintended reprisal has led to anonymised and otherwise data encrypted methods of data collection to protect the identities of research participants. Additionally, it is considered best practice to have referrals for local support services available as research is underway in the event that a research participant requires support.

\section{Potential SOLUTIONS AND LESSONS LEARNED}

\section{A Promising Method 1: Survey-Based Research}

The GSI and the Global Estimates of Modern Slavery have used nationally representative survey-based research to estimate modern slavery. ${ }^{30}$ This research is complemented by available risk modelling to supplement data gaps where surveys are not feasible. Often for nationally representative survey research, a national census is an important starting point to determine sampling frames.

26 US Department of State, Trafficking in Persons Report (Report, June 2019) 37 $<$ https://www.state.gov/reports/2019-trafficking-in-persons-report/>.

27 Global Trends 2017 (n 18) 64, 69.

28 'The Belmont Report', Institutional Review Board (Web Page) $<$ http://www2.umf.maine.edu/irb/other-links/the-belmont-report/>.

29 Martin de Bourmont, 'New US Policy Raises Risk of Deportation for Immigrant Victims of Trafficking', Foreign Policy (online, 2018) <https://foreignpolicy.com/2018/07/09/new-uspolicy-raises-risk-of-deportation-for-immigrant-victims-of-trafficking-immigration-visa/>.

30 GSI (n 2); Global Estimates of Modern Slavery: Forced Labour and Forced Marriage (Report, Walk Free Foundation and International Labour Organisation 2017) $<$ https://www.ilo.org/global/publications/books/WCMS_575479/lang--en/index.htm>. 
However, as with stateless populations, there are important populations vulnerable to exploitation and modern slavery that are not adequately represented in a national census, such as undocumented migrants. One way that modern slavery researchers have begun to address these data gaps includes supplementing census-based stratification efforts with known hot spot data oversample sites to strengthen the existing survey research results.

\section{B Promising Method 2: Multiple Systems Estimation}

Multiple Systems Estimation is a promising method that modern slavery researchers are exploring to better understand measurement in developed countries where many survey-based efforts are ill-suited or cost-prohibitive. ${ }^{31}$ This method allows researchers to analyse concurrent administrative lists of victims for overlaps to estimate how many victims may exist but have not been identified by these sources. ${ }^{32}$ This requirement of administrative data is precisely why this method works best in developed countries that have data management and collection capacity to maintain administrative data on modern slavery victims, while this data management and collection capacity may be more difficult to obtain in developing countries. In this situation, undocumented migrants as well as stateless persons may be unwilling to seek assistance from law enforcement or civil society organisations due to fear of government detection and deportation. Another way this can be addressed in both statelessness and modern slavery research would be to purposefully include organisations that specifically focus on serving these undocumented populations to ensure our best chance to account for these populations.

\section{CONCLUSIONS}

Modern slavery and statelessness research can benefit from shared strategies to overcome the challenges we encounter in serving our hidden populations. The role of measurement is critical to increase political will and available funding in our respective fields, and strategies from the modern slavery field can bolster future investment in statelessness. A shared and symbiotic research agenda emerges in the Americas region to better measure both modern slavery and statelessness and understand the contexts in which both can occur. From protecting our target populations during the research process to motivating unwilling governments, we hope that lessons from modern slavery research may inform ongoing efforts in statelessness research. As demonstrated, there are many opportunities for statelessness and modern slavery researchers to collaborate on our shared commitment to measure and assist these hidden and important populations. Ideally, this symposium may inspire more engagement efforts across our fields in the future.

31 Davina Durgana and Jacqueline Joudo Larsen, 'Using MSE to Measure Modern Slavery in Developed Countries', Delta 8.7 (Web Page, 4 October 2018) $<$ https://delta87.org/2018/10/using-mse-to-measure-modern-slavery-in-developedcountries/ $>$.

32 ibid. 